\title{
Identification of Spinal Neurons in the Embryonic and Larval Zebrafish
}

\author{
ROBERT R. BERNHARDT, AJAY B. CHITNIS, LAURIE LINDAMER, \\ AND JOHN Y. KUWADA \\ Department of Biology (R.R.B., J.Y.K.), Neuroscience Program (A.B.C., L.L., J.Y.K.), and the \\ Institute of Gerontology (J.Y.K.), University of Michigan, Ann Arbor, Michigan 48109
}

\begin{abstract}
Previous studies indicated that the developing fish spinal cord was a simple system containing a small number of distinguishable neuronal cell types (Eisen et al., Nature 320:269-271, '86; Kuwada, Science, 233:740-746, '86). To verify this we have characterized the cellular anatomy of the spinal cord of developing zebrafish in order to determine the number, identities, and organization of the spinal neurons. Spinal neurons were labeled by intracellular dye injections, application of an axonal tracer dye to all or subsets of the axonal tracts, and application of antibodies which recognize embryonic neurons. We found that nine classes of neurons could be identified based on soma size and position, pattern of dendrites, axonal trajectory, and time of axonogenesis. These are two classes of axial motor neurons, which have been previously characterized (Myers, J. Comp. Neurol. 236:555-561, '85), one class of sensory neurons, and six classes of interneurons. One of the interneuron classes could be subclassified as primary and secondary based on criteria similar to those used to classify the axial motor neurons into primary and secondary classes.

The early cord (18-20 hours) is an extremely simple system and contains approximately 18 lateral cell bodies per hemisegment, which presumably are post-mitotic cells. By this stage, five of the neuronal classes have begun axonogenesis including the primary motor neurons, sensory neurons, and three classes of interneurons. By concentrating on these early stages when the cord is at its simplest, pathfinding by growth cones of known identities can be described in detail. Then it should be possible to test many different mechanisms which may guide growth cones in the vertebrate central nervous system (CNS).
\end{abstract}

Key words: growth cones, spinal cord, vertebrate embryos

The most detailed analyses of mechanisms which guide growth cones to their targets have utilized the extremely simple nervous systems of insect embryos (Goodman et al., '84). These investigations have sought to delineate mechanisms by first characterizing the components of the system in as much detail as possible. Once a detailed description of identified growth cones and their environment was made, it was possible to experimentally test the role of specific components within the environment for axonal guidance. These studies demonstrated that insect growth cones followed cell-specific pathways. One way this was done was by highly specific growth cone-cell interactions (Raper et al., '84; Bastiani et al., '86; du Lac et al., '86; Bastiani and Goodman, '86).

Detailed analyses of growth cone guidance are not limited to insect nervous systems but can also be accomplished in some vertebrate embryos. The analysis of pathfinding by the growth cones of motor neurons (Eisen et al., '86), spinal neurons (Kuwada, '86), and brain neurons (Chitnis and
Kuwada, '90) demonstrated that the nervous system of fish embryos is an attractive system for such analyses. We have characterized the cellular anatomy of the spinal cord of zebrafish embryos and larvae in order to see if it contains a small number of distinguishable neurons which would be amenable to a comprehensive analysis of axonal guidance. A comprehensive analysis within one system should allow one to evaluate many different guidance mechanisms. This paper describes the identification of many of the spinal neurons found in the larval and early embryonic cord. The companion paper (Kuwada et al., '90b) characterizes the development of these spinal neurons and the spinal tracts they project into. A third paper (Kuwada et al., 1990a) delineates the cellular environment making up the pathways followed by the growth cones of three classes of spinal neurons.

Accepted August 30, 1990. 


\section{MATERIALS AND METHODS Animals}

Zebrafish embryos and larvae were collected from a laboratory breeding colony and maintained according to the procedures described in Myers et al. ('86).

\section{Procedures for labeling larval and embryonic neurons}

Horseradish peroxidase (HRP) labeling. Larval neurons were backfilled with application of HRP to various locations in the larval CNS. Larvae (3-5 day) were anaesthetized in tricaine methane sulfonate $(0.003 \%$ in water $)$ and immobilized in agar (1.5\% in water). Crystallized HRP was applied to the cord with sharpened tungsten needles. Animals were freed from the agar and allowed to survive for 1-5 hours and then anaesthetized and fixed [ $2 \%$ paraformaldehyde, $1 \%$ glutaraldehyde, $1 \%$ dimethylsulfoxide (DMSO) in $0.1 \mathrm{M}$ phosphate buffer, $\mathrm{pH}$ 7.4] for 1 hour. Following partial dissection of the spinal cord, they were washed, incubated in diaminobenzidene (DAB), and treated with hydrogen peroxide.

DiI labeling. Embryonic neurons were backfilled with diI, 1,1'-dioctadecyl-3,3,3',3'-tetramethylindocarbocyanine perchlorate (Molecular Probes; Honig and Hume, '86) by pressure injection ( $80 \mathrm{psi}, 100 \mathrm{~ms}$ pulse) of a $0.25 \%$ diI solution in $\mathrm{N}, \mathrm{N}$-dimethylformamide from a microelectrode under visual control into discrete regions of the cord. Embryos were dissected to remove the yolk sacs, fixed for 6-10 minutes in 2-4\% paraformaldehyde and $1 \%$ DMSO in phosphate buffer, washed, pinned in a Sylgard (Dow Corning) lined embryo holder, and placed on a fixed-stage Zeiss compound microscope outfitted with differential interference contrast (DIC) optics and epifluorescence. DiI was allowed to spread for 1 hour and the labeled neurons visualized, photographed, or drawn with a camera lucida.

LY labeling. Individual embryonic neurons were labeled by intracellular injection of Lucifer Yellow (LY). Embryos were prepared as described above for dil labeling. Neuronal somata were visualized with DIC optics, impaled with microelectrodes filled with $10 \% \mathrm{LY}$ in distilled water, and filled with dye by injecting hyperpolarizing currents (0.1-0.5 nA for 10-120 seconds). Labeled neurons were then photographed, drawn with a camera lucida, or labeled with HRP using the LY antiserum (see below).

Labeling with antibodies. Embryos were labeled with a monoclonal antibody against acetylated tubulin (Piperno

\section{Abbreviations}

$\begin{array}{ll}\text { CaP } & \text { caudal primary } \\ \text { CiA } & \text { circumferential asending } \\ \text { CiD } & \text { circumferential descending } \\ \text { CoB } & \text { commissural bifurcating } \\ \text { CON1 } & \text { carp optic nerve 1 } \\ \text { CoPA } & \text { commissural primary ascending } \\ \text { CoSA } & \text { commissural secondary ascending } \\ \text { diI } & 1^{\prime}-1^{\prime} \text {-dioctadecyl-3-3-3'-3'-tetramethylindocarbocyanine } \\ \text { DLF } & \text { perchlorate } \\ \text { DoLA } & \text { dorsal longitudinal fasciculus } \\ \text { DRG } & \text { dorsal longitudinal ascending } \\ \text { HRP } & \text { dorsal root ganglion } \\ \text { LY } & \text { horseradish peroxidase } \\ \text { MLF } & \text { lucifer yellow } \\ \text { RB } & \text { medial longitudinal fasciculus } \\ \text { VeLD } & \text { Rohon-Beard } \\ \text { VLF } & \text { ventral longitudinal descending } \\ & \text { ventral longitudinal fasciculus }\end{array}$

and Fuller, '85) as wholemounts by following the procedures for wholemount labeling described in Patel et al. ('89). LY injected neurons were in some cases marked with HRP reaction product by application of a rabbit antiserum to LY (Taghert et al., ' 82 ). Following intracellular injections embryos were fixed in 2-4\% paraformaldehyde and $1 \%$ DMSO in $75 \mathrm{mM}$ phosphate buffer ( $\mathrm{pH} \mathrm{7.4)}$ ) for 30 minutes, washed in buffer, immersed in $0.5-1.0 \%$ collagenase (Sigma Chemical Co., St. Louis, MO, Type 1A) in phosphate buffer for 3-5 minutes, washed, and incubated in 1:500 dilution of LY antiserum with $0.5-1.0 \%$ Triton X-100, 0.5-1.0\% BSA, and $0.5-1.0 \%$ normal goat serum in phosphate buffer overnight at $5^{\circ} \mathrm{C}$. Embryos were then washed, incubated in 1:250 dilution of HRP conjugated goat anti-rabbit with 0.5-1.0\% Triton X-100, 0.5-1.0\% BSA, and 0.5-1.0\% normal goat serum overnight at $5^{\circ} \mathrm{C}$ or for $3-5$ hours at $33^{\circ} \mathrm{C}$, washed, incubated in $\mathrm{DAB}$ for 20 minutes, and reacted by adding hydrogen peroxide. Embryos were labeled with the anti-CON1 monoclonal antibody (Kuwada et al., '87) by following the procedure for anti-LY. In these cases the secondary antibody used was an HRP conjugated goat anti-mouse.

\section{Calculations of soma size}

The cell bodies of HRP-labeled spinal neurons were outlined on a digitizing tablet which computed the area (A) bounded by the outlined soma.

\section{Construction of histograms}

The position of VeLD neurons relative to $\mathrm{CaP}$ motor neurons was determined from acetylated tubulin antibody labeled embryos by dividing each segment into five parts (bins) along the anterior/posterior axis. The distance between consecutive $\mathrm{CaP}$ motor neurons was used to define one segment with the position of $\mathrm{CaP}$ assigned bin 0 . Which bin the center of each VeLD nucleus was located in was then determined and compiled to construct the histogram.

\section{RESULTS \\ Organization of spinal neurons}

The organization of the spinal cord is illustrated schematically in Figure 1. The schematic, representative of trunk segments 5-20, contains all the cell types identified in embryonic and larval cord and is based on findings presented in this paper and on published descriptions of motor neurons (Myers, '85). Each hemisegment contains three primary and a larger number (up to 20 ) of secondary motor neurons. For simplicity the secondary motor neurons have not been included in the schematic, which indicates the approximate soma positions and projection patterns of 8 classes of spinal neurons and the dorsal root ganglion cells.

In addition to Rohon-Beard ( $R B$ ) neurons (see below) and motor neurons, seven classes of interneurons were identified. The interneurons were classified on the basis of soma position, axonal trajectory, soma and axon size, extent of axonal projections, dendritic morphology, and timing of axonogenesis. Axonal trajectories were divided into three basic types; commissural (Co), circumferential (Ci), and longitudinal (L). Commissural neurons had axons which ran ventrally, crossed the ventral midline, and ran longitudinally on the contralateral side. Circumferential neurons had axons which ran ventrally but turned longitudinally ipsilateral to their cell bodies. Longitudinal neurons had 


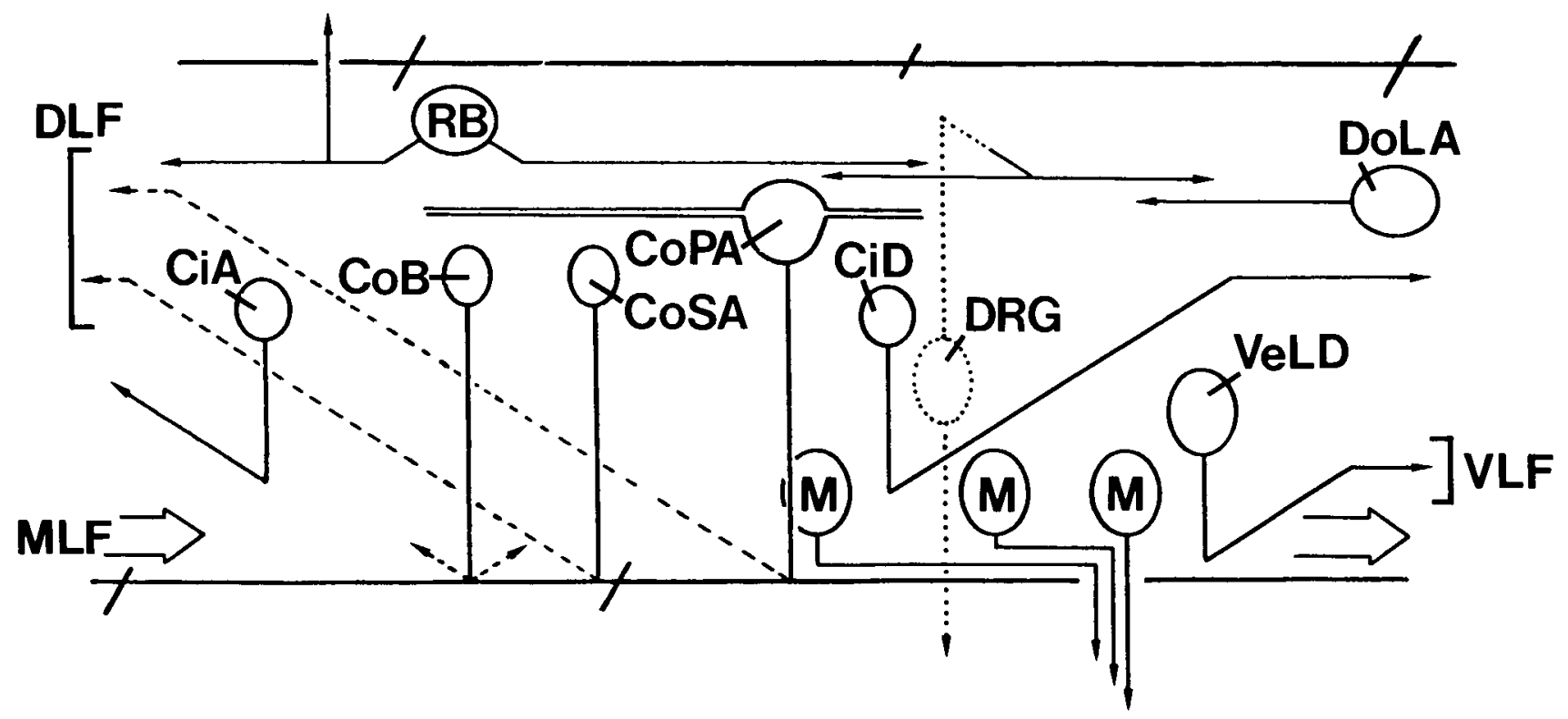

Fig. 1. A schematic summarizing the neuronal classes and major axonal tracts in the spinal cord of developing zebrafish. In this and all other figures, unless otherwise noted, anterior is left, dorsal is up, the segment borders are indicated by diagonal lines, arrows at the ends of

axons which essentially ran longitudinally from their cell bodies without a significant ventrally directed proximal axon. These three basic types of axons were either ascending (A), descending (D), or bifurcated (B). Furthermore, the ascending commissural neurons were subclassified as primary $(\mathrm{P})$ or secondary $(\mathrm{S})$ as explained below, and longitudinal neurons were classified as having dorsal (Do) or ventral $(\mathrm{Ve})$ cell bodies. Our classification provides an operational definition of neuronal classes as a basis for our studies of axonal outgrowth. It remains possible that in some cases different classes may represent morphological variability within a single class of neurons.

Three major tracts in the spinal cord are also illustrated in the schematic. The dorsal (DLF), ventral (VLF), and medial longitudinal fasciculus (MLF) are located in the dorsolateral, ventrolateral, and ventromedial cord, respectively. The longitudinal axonal segments of early spinal neurons are located in the DLF and VLF, and the axons of identified midbrain and hindbrain neurons, which project into the spinal cord, are located in the MLF (Kimmel et al., '82). A detailed description of the different neuronal classes, with the exception of the well-characterized motor neurons, but including the dorsal root ganglion cells, follows below.

\section{Identification of larval spinal neurons}

We identified the long-projecting spinal neurons in zebrafish larvae (3-5 days) by backfilling them with HRP applied to the cord $(n=190)$.

Rohon-Beard (RB) neurons. RB neurons are mechanosensory neurons (Clarke et al., '84) and have large somata [see Materials and Methods for area (A) measurement; $\mathrm{A} \pm$ S.D., $64.1 \mu \mathrm{m}^{2} \pm 14.5 \mu \mathrm{m}^{2}, \mathrm{n}=11$ ] located dorsolaterally in the cord (Fig. 2). RB neurons were backfilled from caudal applications of HRP. The number of backfilled cells per spinal hemisegment varied between one and four. RB cells have two thin, ipsilateral longitudinal axons indicate that the axons extend further, and contralateral axons and somata are indicated by dashed lines. Peripheral portions of the DRG neuron are indicated by dots. M, primary motor neuron. See text for all other abbreviations.
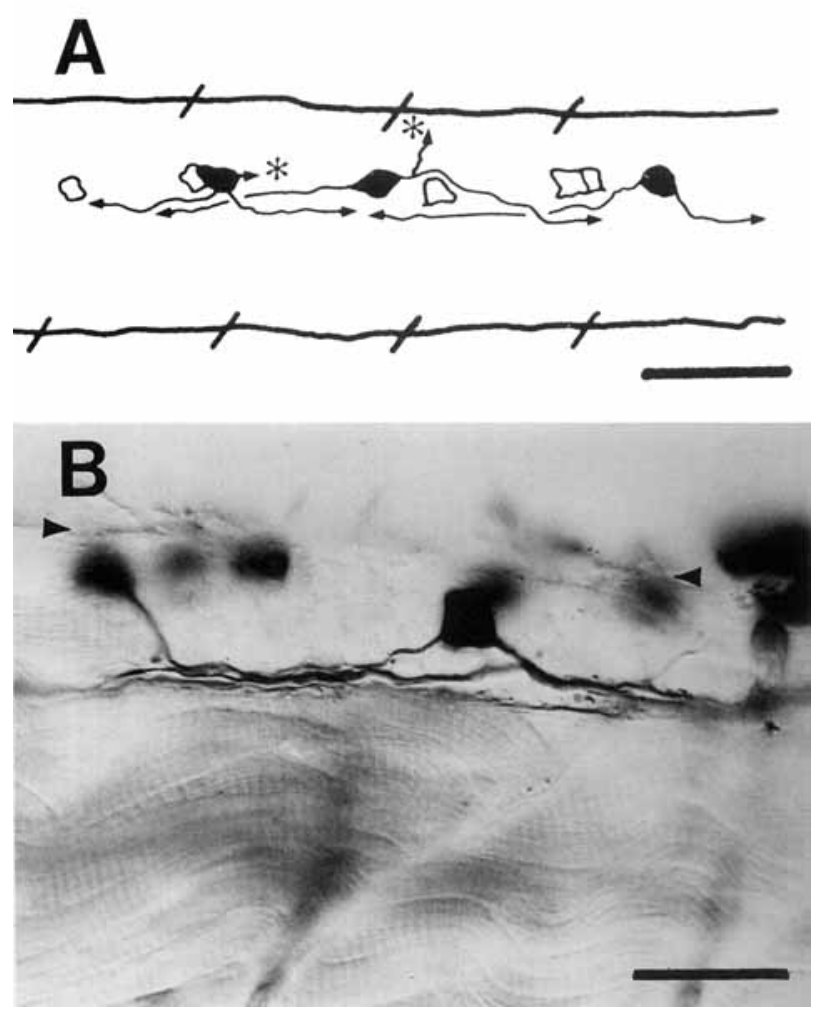

Fig. 2. Larval (4-day) RB neurons backfilled with HRP. A: Camera lucida drawing of $\mathrm{RB}$ cells showing their two longitudinal spinal axons and peripheral axons (asterisks). The axons are long and extend beyond the segments illustrated (arrows). Scale, $50 \mu \mathrm{m}$. B: Photomicrograph of RB cells. Arrowheads, dorsal boundary of the cord. Axial muscles lateral to the cord can be seen ventral to the RB cells. Scale, $25 \mu \mathrm{m}$. 
axons: one ascending and the other descending. The initial axon segments are directed ventrally from the cell bodies so that their longitudinal axons are located ventral to their somata. The ascending axon can extend over more than 20 segments. The descending axon is shorter; based on the distribution of somata backfilled from caudal HRP application sites, it extends approximately ten segments. RB longitudinal axons form a loosely fasciculated fiber bundle in the DLF, which occupies a dorsalmost position in the marginal fiber zone. The ascending axons terminate in the hindbrain (see below). Peripheral input to the spinal cord is provided by a peripheral axon which usually arises in the vicinity of the soma as a sidebranch of the longitudinal axon. The peripheral axon branches profusely underneath the skin (not shown).

Ascending commissural interneurons. The ascending commissural neurons can be subdivided into commissural primary ascending (CoPA) and commissural secondary ascending (CoSA) populations based on their cell body size and location, distribution, axonal caliber, and dendritic morphology.

CoPA neurons. CoPA cells (Fig. 3) are among the largest in the spinal cord $\left(88.7 \mu \mathrm{m}^{2} \pm 21.5 \mu \mathrm{m}^{2}, \mathrm{n}=13\right)$, with a spherical soma or soma elongated along the rostral/ caudal axis and soma. They are significantly larger than RB (Student's t test, $\mathrm{t}=3.22, P<0.01$ ) and the CoSA neurons (see below; Student's $t$ test, $t=6.86, P<0.001$ ). They are located in the dorsal cord ventral to the $R B$ cells. Two distinct dendrites emerge from the rostral and caudal poles of the cell body and run longitudinally for up to four spinal segments. The dendrites are unbranched but decorated with a few short, stubby processes. The two dendrites, together with the ventrally emerging axon, give the CoPA-cell its characteristic T-shape. HRP backfills reveal no more than one CoPA neuron per spinal hemisegment.

The commissural axon extends ventrally, either straight or at an oblique, rostrally directed angle. After crossing the ventral midline, the axon runs along an oblique trajectory both dorsally and rostrally. Within 1-2 segments rostral to the soma it reaches the DLF in the lateral marginal zone. There it extends longitudinally, sometimes in close vicinity to the longitudinal dendrites of contralateral CoPA cells. CoPA axons are thick, of similar caliber as the dendrites, and without sidebranches.

An interesting exception to the normal dendritic branching pattern is illustrated in Figure 3C. In this cell the descending dendrite and the commissural axon arise nor-

\section{A}

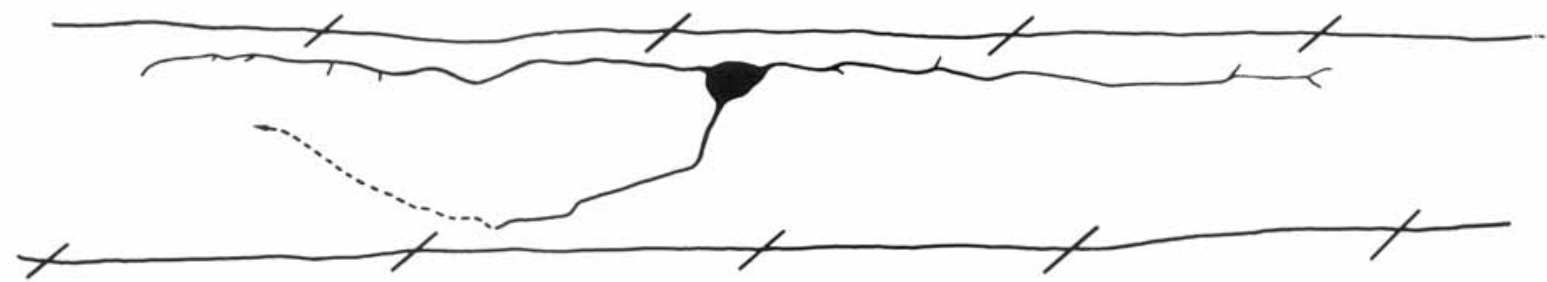

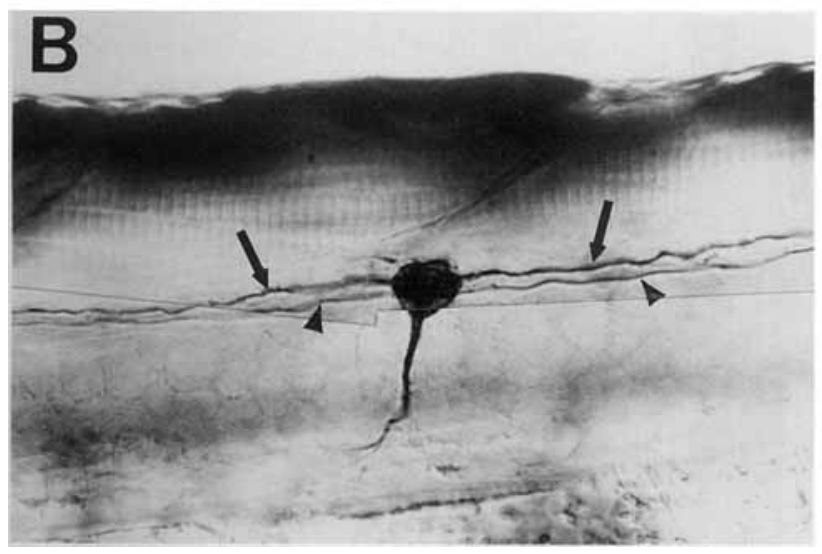

Fig. 3. CoPA neurons backfilled with HRP from a 4-day larva. A: Camera lucida drawing showing the large CoPA cell body and two long dendrites which extend longitudinally in the DLF. Scale, $50 \mu \mathrm{m}$. B: Photomicrograph showing that the dendrites (arrows) extend parallel to the longitudinal axons of a contralateral CoPA cell (arrowheads). Axon goes out of the focal plane in the ventral cord. C: Atypical CoPA

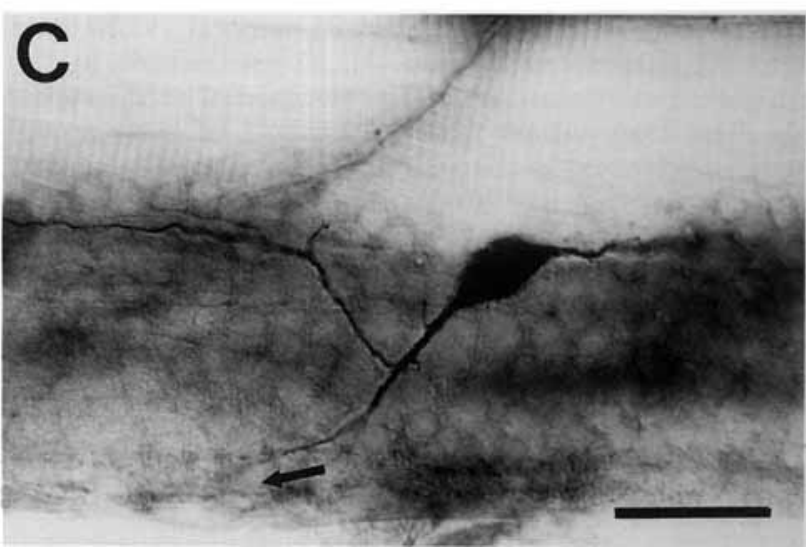

cell with the ascending dendrite arising from the initial axon segment rather than the cell body (compare to A,B). After initially running dorsally the dendrite extends longitudinally in its normal location. Arrow denotes that axon goes out of the focal plane. Scale for B,C, 25 $\mu \mathrm{m}$. 
mally from the cell body. The ascending dendrite, however, originates as a sidebranch from the initial axon segment. This dendrite initially runs rostrodorsally and turns longitudinally at the same dorsal/ventral level as the soma. One way this trajectory may have arisen is by course correction by the growing dendrite.

CoSA neurons. CoSA cells (Fig. 4) occupy positions just ventral to the level of the CoPA cells. CoSA somata are smaller than those of CoPA cells $\left(49.8 \mu \mathrm{m}^{2} \pm 9.6 \mu \mathrm{m}^{2}\right.$, $\mathrm{n}=20$ ) and generally oval shaped, with the long axis running dorsoventrally, in contrast to CoPA cells, which normally are either rounded or elongated along the rostrocaudal axis. CoSA cells most notably differ from CoPA cells in their lack of somatic dendrites and have smaller caliber axons. They are more numerous than CoPA cells with HRP backfills revealing up to five per spinal hemisegment.

The axonal trajectory of the CoSA cell resembles that of the CoPA cell. After extending to the ventral midline, the CoSA axons cross contralaterally and continue at an oblique, rostrodorsal angle to reach the DLF. There the thin axons are lost among other HRP labeled longitudinal fibers. CoSA axons may extend no more than ten segments since labeled CoSA neurons were always within ten segments caudal to the HRP application site. Alternatively, they may be difficult to backfill due to the small caliber of their axons although RB neurons also have thin axons and were readily backfilled for longer distances.

Circumferential descending (CiD) neurons. The $\mathrm{CiD}$ cells are situated just ventral to CoSA cells, which they resemble in size $\left(52.7 \mu \mathrm{m}^{2} \pm 14.2 \mu \mathrm{m}^{2}, \mathrm{n}=15\right)$ and soma shape. Occasionally, small dendritic branches emerge from the dorsal apex of the cell body (Fig. 5). Other CiD cells have short, ventrally directed dendritic sidebranches, which arise from the initial axon segment. Up to three CiD cells per spinal hemisegment were labeled by HRP applied to the cord.

The CiD cell has only an ipsilateral axon. Its axon arises from the ventral pole of the soma, initially runs ventrally, and turns caudally and dorsally before reaching the ventral midline. It then runs along a caudodorsal trajectory for over

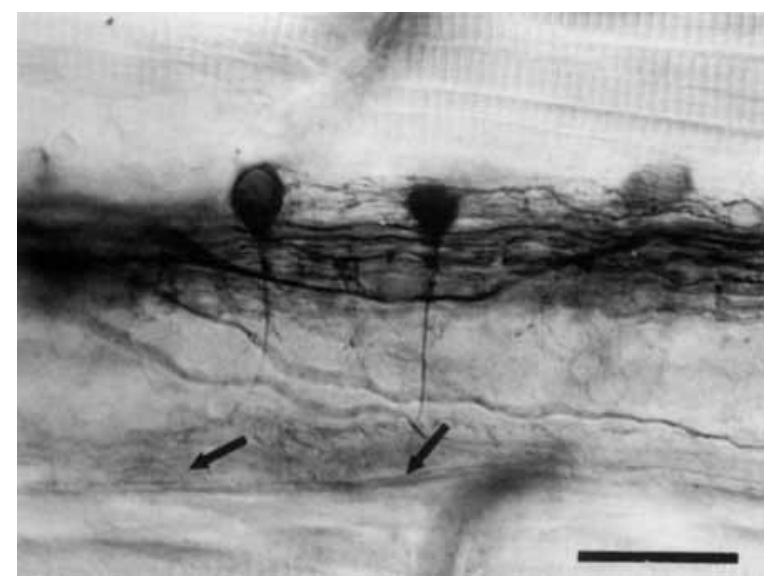

Fig. 4. CoSA neurons backfilled with HRP in a 4-day larva. Micrograph of two CoSA neurons showing their ventrally directed axons which cross contralaterally (arrows) in the floor region of the cord. Ascending axons, originating from contralateral commissural somata, can be seen traversing obliquely from the floor of the cord towards the DLF, from lower right to upper left. Scale, $25 \mu \mathrm{m}$.
1-2 segments before it continues longitudinally in the lateral marginal zone. The longitudinal axon is located ventral to the RB and CoPA axons in the DLF. The thin axon cannot be traced over long distances because it is lost among the other labeled fibers of the marginal zone.

In addition to the descending axon, some $\mathrm{CiD}$ neurons (approximately $30 \%$ of the cells observed) also have an axonal sidebranch, which arises from the main axon and ascends ipsilaterally in the cord. The ascending axon collateral appears to be short: backfilled somata located caudal to the HRP application site were very rare and confined to the adjacent $1-2$ segments.

Ventral longitudinal descending (VeLD) neurons. VeLD cells (Fig. 6; $53.7 \mu \mathrm{m}^{2} \pm 10.1 \mu \mathrm{m}^{2}, \mathrm{n}=27$ ) are located in the ventral cord, slightly dorsal to the primary motoneurons and ventral to the CiD neurons. VeLD cells have extensive dendritic arborizations, which can cover the length of one segment. Dendrites are generally confined to the ventral half of the cord but occasionally extend towards the DLF (not shown). Often the dendritic fields of adjacent cells overlap. Up to two VeLDs per spinal hemisegment could be backfilled with HRP.

The VeLD axon emerges from the ventral pole of the cell body and initially runs ventrally. It passes lateral to the Mauthner axon before turning caudally. The axon cannot be traced among the heavily labeled fibers of the MLF; therefore the exact location of the longitudinal axon is obscured. However, the VeLD axons likely occupy a subregion of the marginal zone in the ventrolateral cord (VLF), which is distinct from the MLF since longitudinal VeLD axons form a bundle dorsal and lateral to the MLF in the embryo (Kuwada et al., '90b).

Dorsal root ganglion ( $D R G$ ) neurons. Occasionally, HRP applications to the spinal cord label DRG cells, located lateral to the spinal cord at the level of the ventral roots. DRG cells are also labeled by an antibody to acetylated tubulin (Fig. 7). Both HRP backfills and acetylated tubulin antibody labeling reveal large, oval-shaped, bipolar cells, with a centrally directed and a peripheral axon arising from the dorsal and ventral poles of the soma, respectively. Surprisingly there is only one DRG cell, which has undergone axonogenesis, per trunk hemisegment in 3- to 4-dayold larvae.

HRP backfills show that the central axon of the DRG cell bifurcates upon entering the spinal cord, giving rise to an ascending and a descending axon in the DLF. Accordingly, backfilled somata are found both rostral and caudal to an HRP application site. The ascending and descending spinal axons, which could not be traced among the other labeled axons in the dorsolateral marginal zone, appear to be of similar length, as judged from the distribution of the backfilled DRG cells. Labeled somata were confined to within ten segments, centered at the HRP application site. The peripheral axon runs ventrally, midway in its segment without branching.

Supraspinal projections of $R B$ and commissural neurons. In 4-day larvae labeled by application of HRP to the caudal end of the cord, RB axons can be traced through the DLF and into the hindbrain (Fig. 8). They course by the lateral dendrite of the Mauthner neuron and terminate at the level of the otocyst (Fig. 8B).

In addition to the ascending axons, several reticulospinal neurons, including the distinct Mauthner neuron, as well as cells in the mesencephalic nucleus of the MLF, have been 

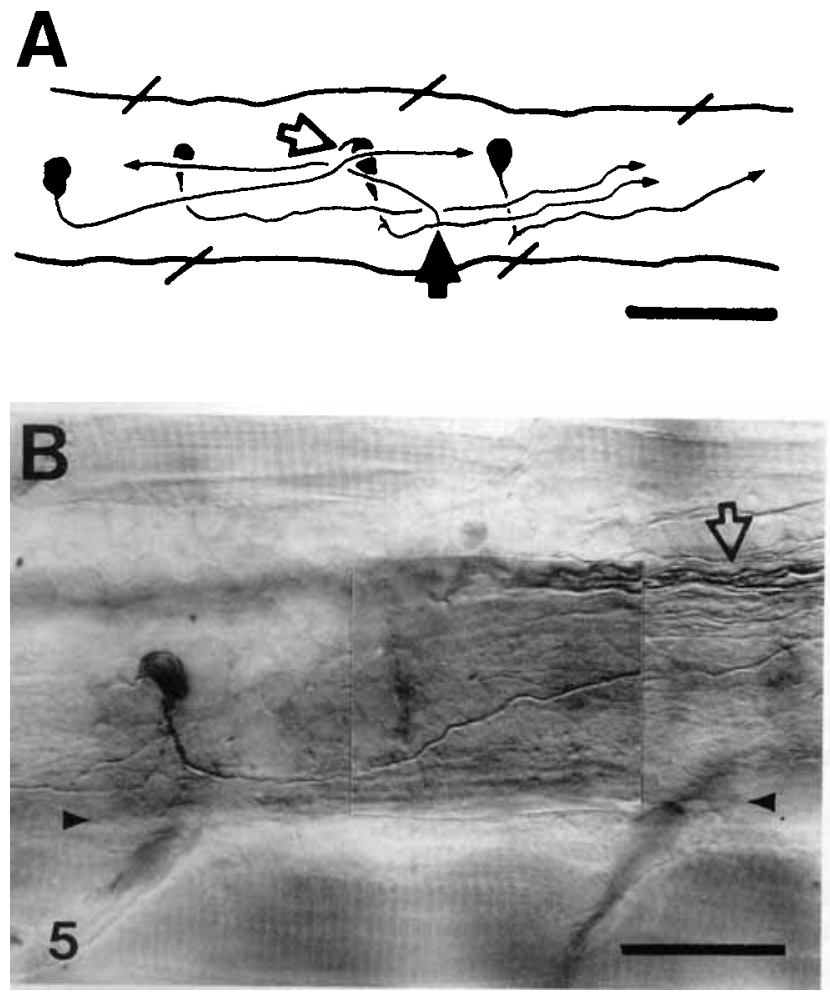

Fig. 5. HRP backfilled $\mathrm{CiD}$ neurons in a 4-day larva. A: Camera lucida drawing showing several backfilled CiD cells. Their axons initially run ventrally, turn to follow a caudodorsal trajectory, and ultimately run caudal in the dorsal cord. One axon branches (filled arrow) and gives rise to an ascending axon collateral. The proximal segment of a dendrite is indicated by the open arrow. Scale, $50 \mu \mathrm{m}$. B: A photomicrograph showing a CiD cell with an unbranched axon and several short, ventrally directed dendrites. After extending ventrally the axon runs towards the DLF (open arrow). Arrowheads, ventral border of the cord. Scale, $25 \mu \mathrm{m}$.

backfilled (Fig. 8) through their axons which descend in the MLF. These neurons have been studied extensively (Kimmel et al., ' 82; Mendelson, '86) and are not discussed here.

In the brain the axons of the ascending commissural cells (Fig. 9) ascend lateral to the reticulospinal neurons and the nucleus of the MLF and terminate just caudal to the evagination of the telencephalon. Comparisons with brains in which axons were labeled by the acetylated tubulin antibody and with sections through the larval brain indicate that the terminals are located near the diencephalon/ mesencephalon border near the postoptic commissure (see Chitnis and Kuwada, '90). Before reaching the termination site, the axons give off collaterals which terminate lateral to the nucleus of the MLF.

The terminals and their long, thick axons were identified as belonging to ascending commissural neurons based on several lines of evidence. First, of all spinal neurons identified in the present study, only RB and commissural axons were found to project supraspinal axons. Since RB cells terminate at the level of the hindbrain, the diencephalic projection are likely to arise from the ascending commissural cells. Second, applications of HRP confined to the ventral spinal cord in the vicinity of the floor plate label the reticulospinal axons in the MLF and commissural cells,
A
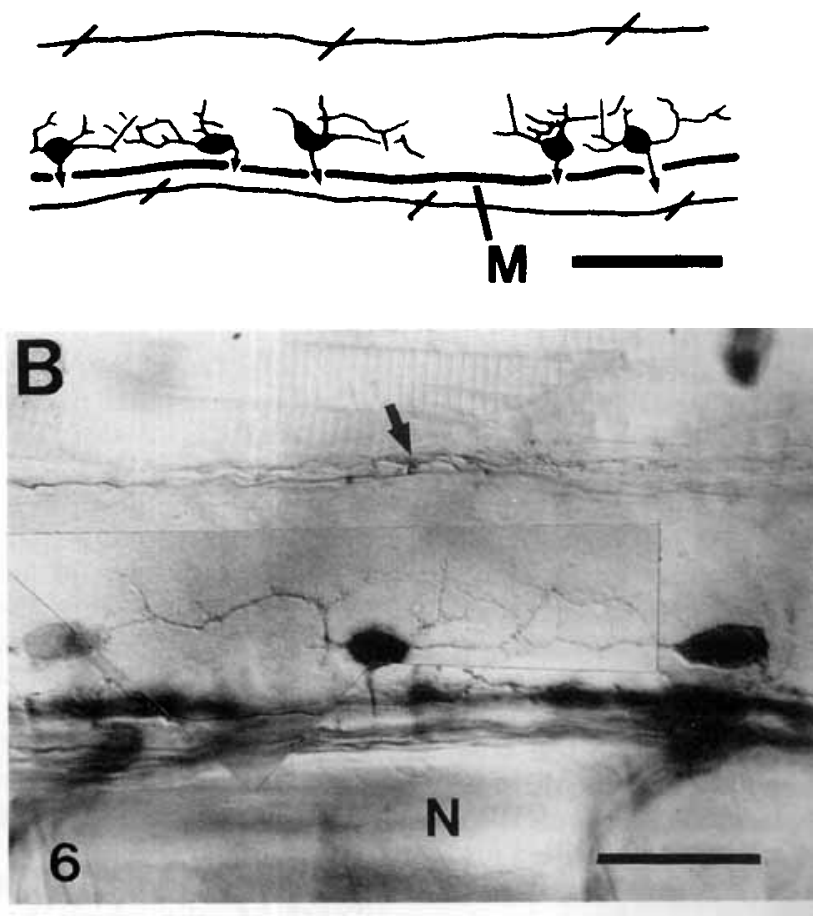

Fig. 6. VeLD cells backfilled with HRP in a 4-day larva. A: Camera lucida drawing showing $1-2$ VeLD neurons per hemisegment. Their axons initially run ventrally, below the level of the Mauthner axon (M), which indicates the location of the MLF. Their longitudinal axons usually could not be traced through the heavily labeled MLF. Scale, 50 $\mu \mathrm{m}$. B: Photomicrograph showing that VeLD cells give rise to dendrites which overlap and generally extend laterally but occasionally reach towards the DLF (arrow). N, notochord; scale, $25 \mu \mathrm{m}$.

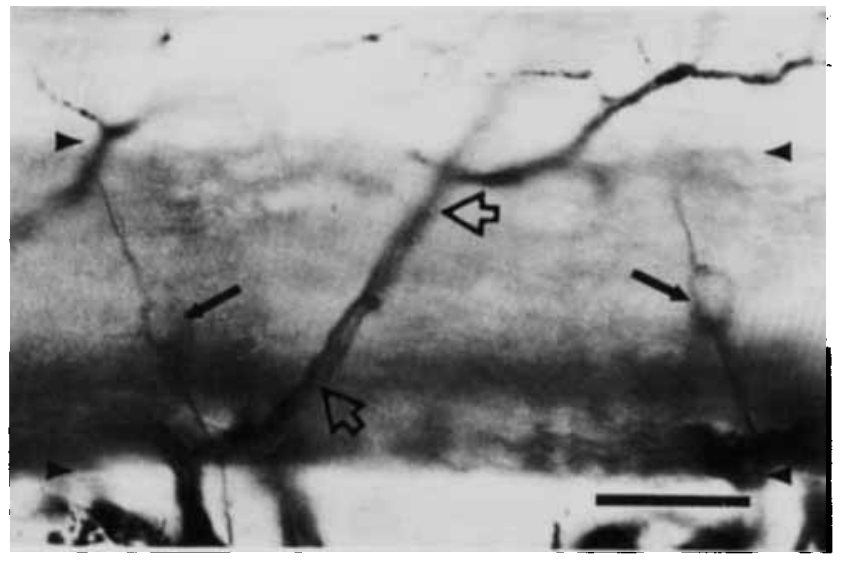

Fig. 7. Micrograph of two DRG neurons (solid arrows) labeled with an antibody against acetylated tubulin in a 3-day larva. In young larva there is only a single DRG cell with axons per spinal hemisegment. Motor nerves are also labeled (open arrows). The dorsal and ventral borders of the out of focus spinal cord are indicated by arrowheads. Scale, $25 \mu \mathrm{m}$. 


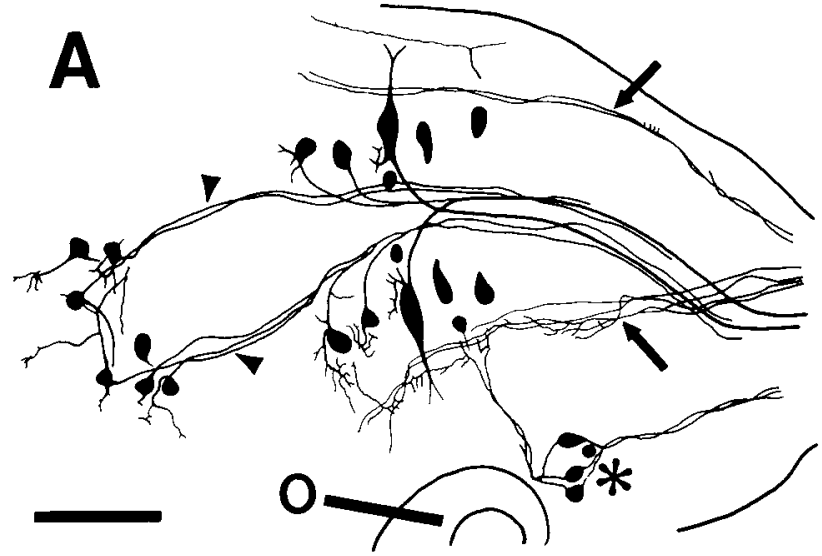

Fig. 8. The termination sites of RB cells in the larval hindbrain. A: Camera lucida drawing of the hindbrain and midbrain seen from a dorsal perspective showing that the ascending RB axons (arrows) course by the Mauthner cell dendrite and terminate near the otocyst (O). Midbrain and hindbrain neurons which give rise to the MLF

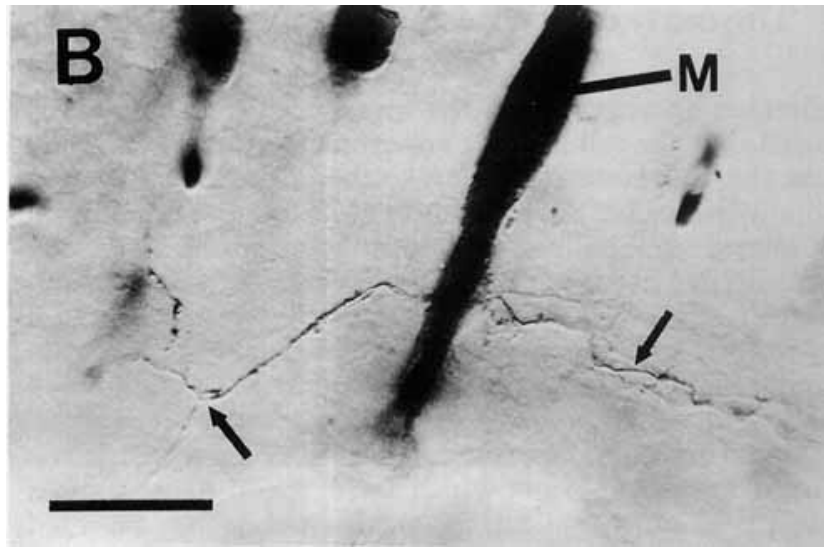

(arrowheads) have been backfilled. The Mauthner cell is the largest cell medial to the otocyst. Also labeled are cells of the lateral line ganglion (asterisk). Scale, $50 \mu \mathrm{m}$. B: Micrograph of an RB axon and terminal (arrows) in the vicinity of the Mauthner cell (M). Anterior, left; medial, up; scale, $25 \mu \mathrm{m}$.

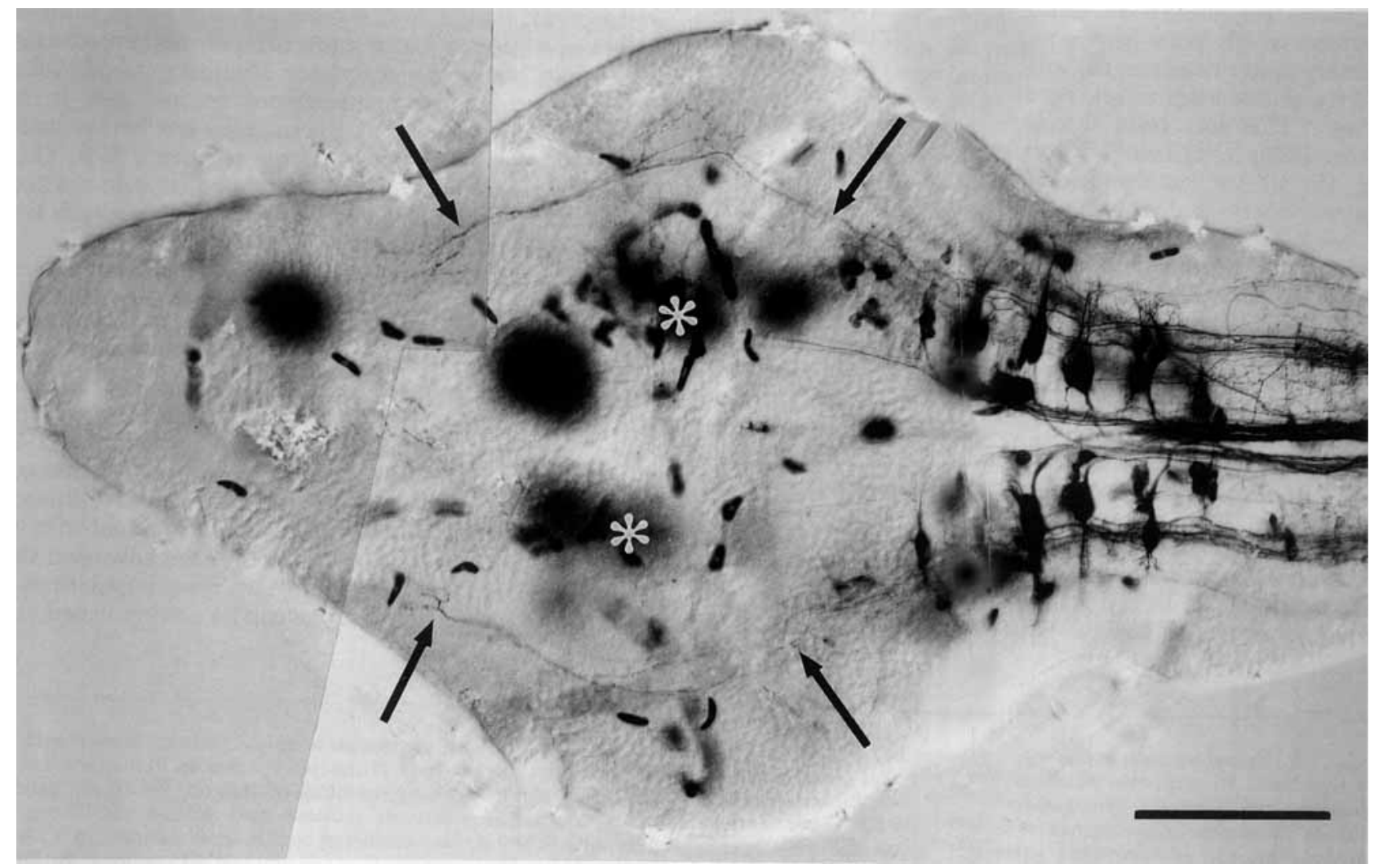

Fig. 9. The terminal fields of the axons of the ascending commissural neurons near the diencephalon/mesencephalon border of a 4-day larva. Micrograph of HRP labeled commissural axons (arrows) seen in a ventral view of the wholemounted brain. Also labeled are hindbrain neurons (to the right) and the nucleus of the MLF (asterisks). The bundled commissural axons ascend lateral to the nucleus of the MLF and terminate near the diencephalon/mesencephalon border, caudal to the evagination of the telencephalon. Anterior, left. Scale, $100 \mu \mathrm{m}$. through their commissural axon segments. In these cases where no other neurons projecting into the DLF were labeled, the ascending axons terminated in the diencephalon (not shown). Third, application of HRP to the dienceph- alon backfills ascending commissural cells in the spinal cord exclusively (not shown). Together, these observations indicate that ascending commissural cells provide a direct spinal input to the forebrain of zebrafish. 


\section{The early cord contains a small number of neurons}

Electron micrographs of the spinal cord of fish embryos showed that the cell bodies of neurons are located laterally while the cell bodies of neuroepithelial cells are located medially (Kuwada, '86; Kuwada et al., '90b). Presumably all the lateral cell bodies represent post-mitotic cells. By counting the lateral cell bodies in the zebrafish cord visualized with DIC optics, we estimated that there are 18.3 post-mitotic cells per hemisegment (range: 13-25, counts from 20 hemisegments in eight embryos) in segments 6-9 of 18-20-hour embryos. A monoclonal antibody against acetylated tubulin (Piperno and Fuller, '85), which labels many if not all neurons which have begun axonogenesis (Siddiqui et al., '89; Chitnis and Kuwada, '90), revealed 4.28 neurons per hemisegment (range: $1-7$, counts from 28 hemisegments in eight embryos) in the same segments of 18-hour embryos. Both these results suggest that the early cord contains a small number of neurons.

\section{Identification of embryonic spinal neurons}

Earliest spinal neurons. At 18-20 hours the trunk segments (segments 5-15) of the cord contain five classes of neurons which have begun axonogenesis. These are the primary motor neurons, RB, ascending commissural, VeLD, and the dorsal longitudinal ascending (DoLA) neurons (see below). This has been demonstrated in four ways. 1) Intracellular injection of LY into lateral cell bodies ( $n=128$; Fig. 10). 2) Application of a monoclonal antibody directed against acetylated tubulin to wholemounted embryos ( $n=40$; Fig. 11). This antibody darkly labels the axons and their initial segments, but sometimes lightly labels the neuronal cell bodies in zebrafish embryos. 3) Application of the lipophilic dye, diI, (Honig and Hume, '86) to the cord to backlabel spinal neurons in 16-18-hour embryos $(n=30)$ and 22-25-hour embryos $(n=30)$ and 22-25-hour embryos ( $\mathrm{n}=30$; Fig. 12). 4) Application of anti-CON1 monoclonal antibody (Kuwada et al., ' 87 ), which prior to 28 hours recognizes a subset of spinal neurons that have started axonogenesis, the RB, and a subset of commissural neurons ( $\mathrm{n}=20$; Fig. 13).

$\boldsymbol{R B}$ neurons. In early embryos the $\mathrm{RB}$ neurons are the most dorsal neurons in the cord and have ascending and descending axons in the DLF (Figs. 10A, 11, 12A). When impaling neuronal somata with LY-filled electrodes, the adjacent neuroepithelial cells become labeled through their endfeet processes which overlie the neuronal somata (see Fig. 10). The labeled neuroepithelial cells are probably not a result of dye coupling since the embryos are fixed prior to injections (see Materials and Methods). Furthermore, we have confirmed that the filled structures adjacent to the neuronal somata are not part of the neuron by backfilling neurons with diI and by labeling neurons with the acetylated tubulin and anti-CON1 antibodies.

There are 1.1 RB cells per hemisegment (range: 0-2; segments 5-8 in five embryos) labeled with the acetylated tubulin antibody and $1.1 \mathrm{RB}$ cells per hemisegment (range: 1-2; segments 4-7 in nine embryos) backlabeled with diI applied to the dorsal cord at 18 hours. Since both the acetylated tubulin antibody and diI only label neurons that have already begun axonogenesis, this distribution probably represents $\mathrm{RB}$ neurons with axons. The fact that $80 \%$ of the RB neurons are born by the completion of gastrulation in amphibian embryos (Lamborghini, '80) and that there are 1-4 RB cells per hemisegment in larvae (see previous section) suggests that many $\mathrm{RB}$ neurons have not yet developed axons at this time. In fact counts of the large, most dorsal somata suggest there are $3.3 \mathrm{RB}$ cells per hemisegment (range: $2-5$; segments $6-9$ in seven embryos) in 18-hour embryos. Later more RB neurons project axons since by 24 hours the acetylated tubulin antibody labels 2.55 RB neurons per hemisegment (range: 1-5, in ten embryos) and dil labels $2.1 \mathrm{RB}$ neurons per hemisegment (range: 1-3 in nine embryos) from segments 6-9. These findings also confirm that the acetylated tubulin antibody labels most if not all of the embryonic neurons which have already projected axons.

Ascending commissural neurons. Located just ventral to the RB cells in the 18-hour cord are relatively large commissural neurons with ascending growth cones and axons in the dorsolateral cord (Fig. 10B, 11). The ascending axons are likely located in the DLF since discrete injections of diI into the dorsolateral cord backfills ascending commissural neurons as well as RB and DoLA neurons in 22-25hour embryos (Fig. 12B). LY fills of several commissural neurons in the cord of older embryos reveal numerous ascending commissural interneurons in a segment with one of them having a growth cone much more advanced than the others (Fig. 14A). Furthermore, two populations of ascending commissural neurons can be distinguished anti-
Fig. 10. Spinal neurons in 20-hour embryos labeled by intracellular LY injections. In each case adjacent neuroepithelial cells have been labeled as well (see text). Triangles indicate the ventral border of the cord. A: Fluorescence photograph of an LY filled RB neuron. Arrow signifies that the anterior axon extended beyond the photograph; asterisk, peripheral axon. B: LY filled ascending commissural neuron. This is a photomontage which displays the soma and the contralateral growth cone and axon in focus simultaneously. Arrow denotes the point where the axon crosses the ventral midline; N, notochord. C: LY/ anti-LY labeled DoLA neuron. Also labeled are two commissural neurons to the right of the DoLA soma. Outlines of the axial muscle segments can be seen as chevron shaped structures. D: LY labeled VeLD neuron. Arrow denotes the VeLD soma which is ventral to the line of neuroepithelial cells the electrode passed through in order to impale the VeLD soma. Scale for A and B, $100 \mu \mathrm{m}$; for C, $50 \mu \mathrm{m}$; for D, $200 \mu \mathrm{m}$.
Fig. 11. The five earliest classes of spinal neurons labeled with the acetylated tubulin antibody. Numerals 1-5 denote, in numerical order, RB, DoLA, early ascending commissural neuron, VeLD, and primary motor neurons. Arrowheads indicate cord outline. A: Micrograph showing RB, DoLA, and ascending commissural neurons in a 18-19hour embryo. One segment is approximately $50 \mu \mathrm{m}$ long. B: Micrograph showing ascending commissural, VeLD, and primary motor neurons from a 16-17-hour embryo. The emerging axon of the primary motor neuron is out of the focal plane and is indicated by an arrow. Scale for A and B, $50 \mu \mathrm{m}$.

Fig. 12. Spinal neuronal types backlabeled by discrete injections of diI into the dorsolateral cord of 24-hour embryos. Triangles indicate outline of the cord. A: Fluorescence photograph of backlabeled RB (arrows) and DoLA (asterisk) neurons in a 24-hour embryo following an application of diI to the dorsolateral cord, which can be seen on the left side of the photograph. B: Fluorescence photograph of backlabeled ascending commissural neurons on the contralateral side of the preparation shown in $\mathrm{A}$. Scale for $\mathrm{A}$ and $\mathrm{B}, 50 \mu \mathrm{m}$. 


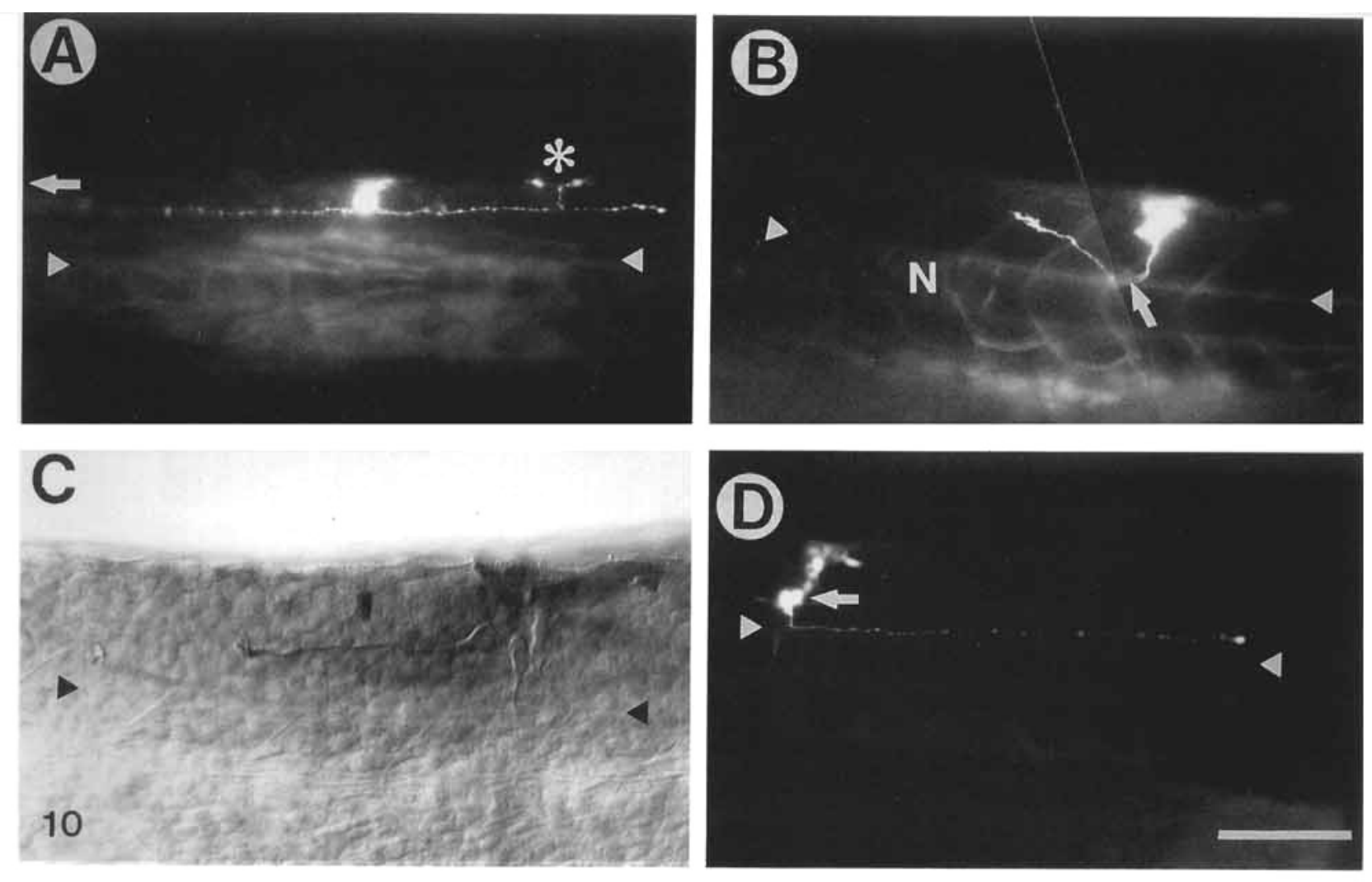

Figure 10

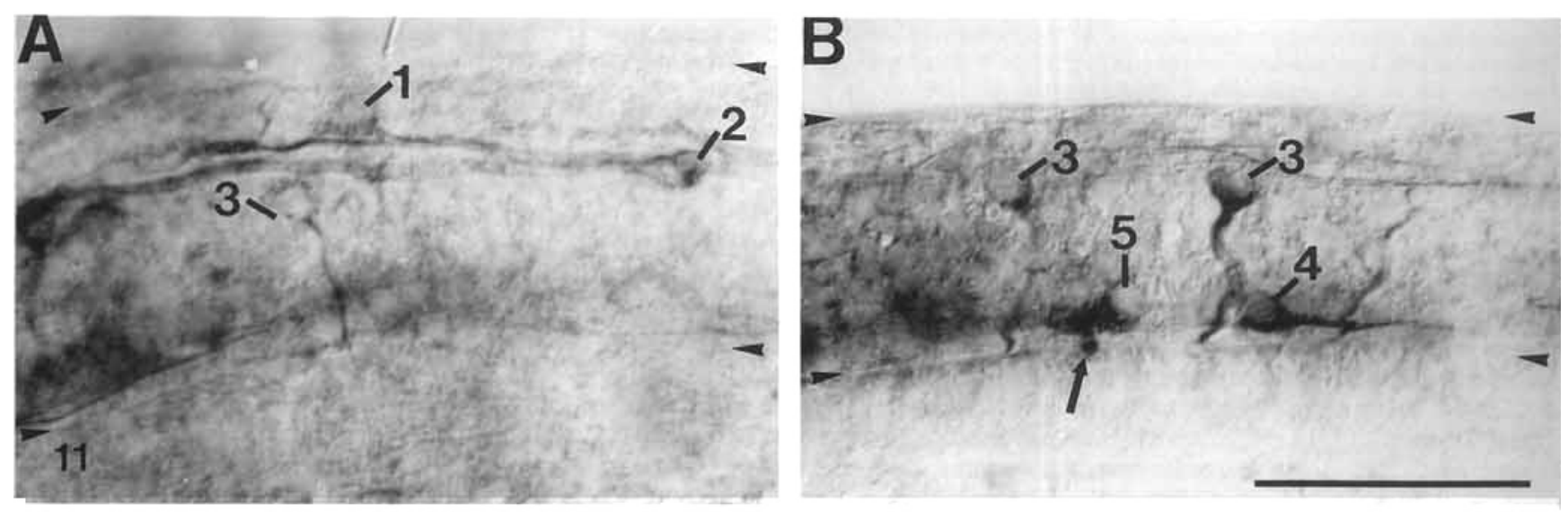

Figure 11

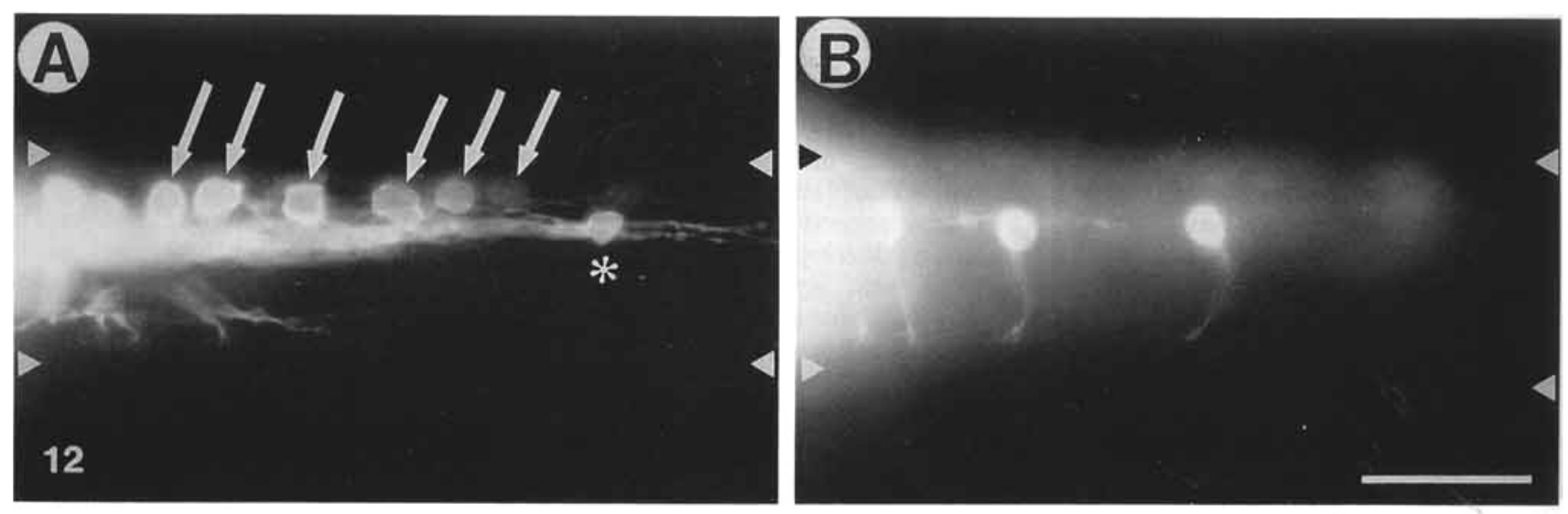



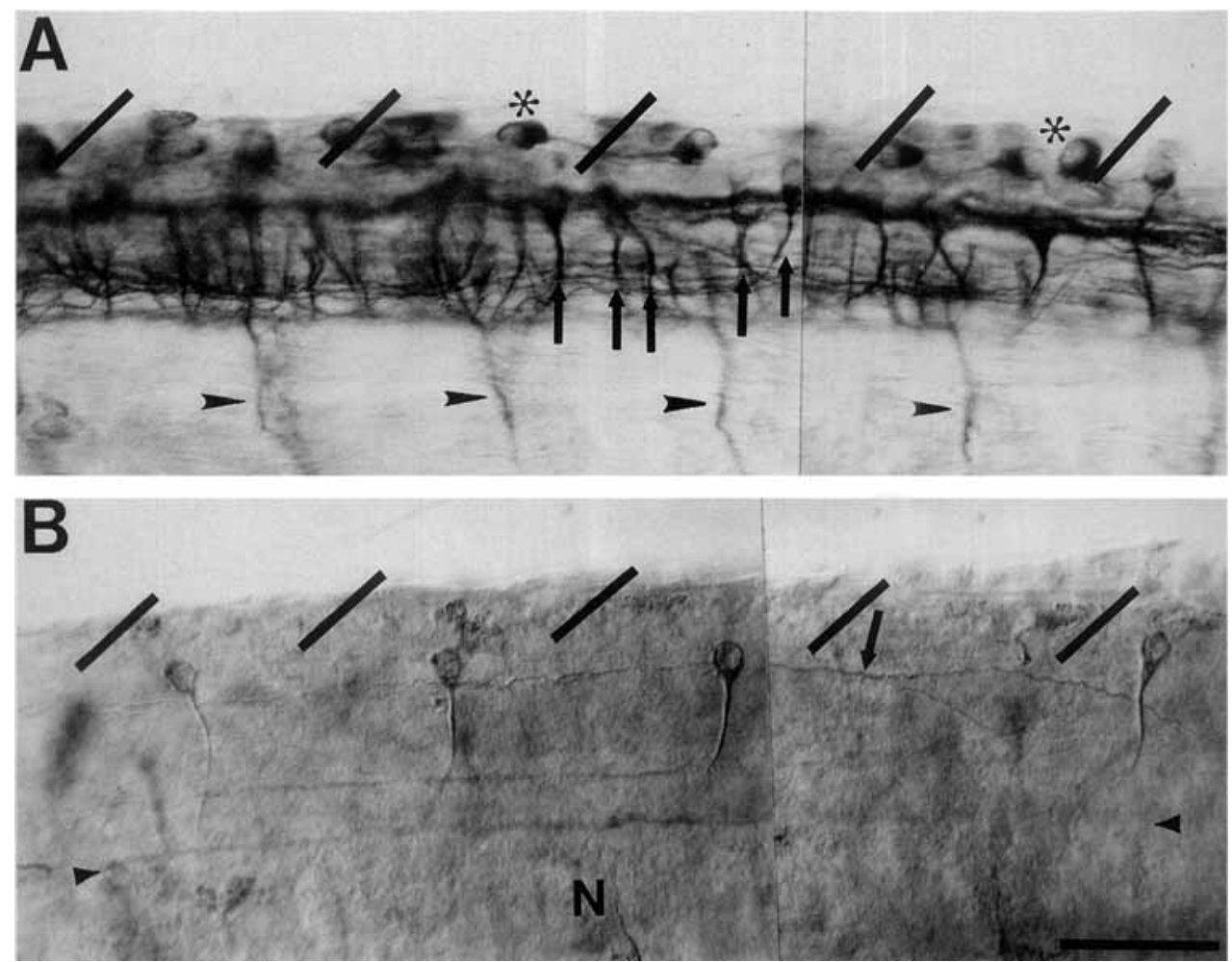

Fig. 13. A large ascending commissural neuron is antigenically distinct from other commissural neurons. A: Distribution of acetylated tubulin labeled commissural neurons in segments $7-11$ of a 28 -hour embryo. Up to five commissural cells (arrows) are labeled in one hemisegment. Asterisks denote two of the dorsally located RB neurons. Arrowheads indicate the spinal nerves. The DLF can be seen as a thick

genically in the embryo up to 28 hours. The acetylated tubulin antibody labels many if not all commissural neurons that have projected axons, while anti-CON1 typically labels a single ascending commissural neurons per hemisegment in 28-hour embryos (Fig. 13). Commissural neurons labeled by the acetylated tubulin antibody begin to appear at 17-18 hours but continue to increase in number up to at least 28 hours (data not shown). However, the full complement of CON1 positive commissural neurons seen at 28 hours (0.87 neurons per hemisegment; range: $0-2$ in segments $6-11$ in ten embryos) appears at $17-18 \mathrm{hr}(0.88$ neurons per hemisegment; range: $0-2$ in segments $6-10$ in six embryos). This corresponds with the distribution of CoPA neurons seen in the larval cord. Although most often there was a single CON1 positive commissural neuron per hemisegment, the distribution of CON1 positive commissural neurons appears not to be strictly segmental. In 18 of 60 segments CON1 positive commissural neurons are found on one side but not the other in segments 6-11 of ten 28-hour embryos. By 32 hours anti-CON1 positive ascending commissural neurons $(n=12)$ have begun to develop CoPA-like dendrites from the cell body (Fig. 14B). By 48-hour diI backfills ( $\mathrm{n}=2$; Fig. 14C) and LY injections ( $\mathrm{n}=4$; not shown) of large, ascending commissural neurons show that they possess relatively mature looking somatic dendrites. These indirect observations suggest that up to 28 hours the CON1 positive commissural neuron may be the CoPA neuron and the CON1 negative ones CoSA neurons (see Discussion). fascicle of axons at the level of the commissural cell bodies. B: Distribution of anti-CON1 labeled ascending commissural neurons in segments $7-11$ of a 28 -hour embryo. Note there is a commissural neuron in each segment except segment 10. Arrow, longitudinal axons of contralateral commissural neurons; arrowheads, ventral border of the cord; $N$, notochord; scale for A and B, $50 \mu \mathrm{m}$.

DoLA neurons. All the early neurons have their counterparts in the larval cord with the exception of the DoLA neuron. The DoLA neuron is an interneuron with an ascending longitudinal axon in the DLF (Figs. 10C, 11, $12 \mathrm{~A})$. Its cell body is found just ventral to the RB somata. In the embryonic cord there are relatively few DoLA neurons with many segments containing none; in Figure 11 one DoLA neuron is labeled by the acetylated tubulin antibody in the several segments shown. Assuming that the acetylated tubulin antibody labels all DoLA neurons with axons, there is 0.06 DoLA neuron (range: $0-1$; segments 5-8 in four embryos) per hemisegment at 18 hours. This low frequency is corroborated by intracellular LY injections and diI labeling of dorsal neurons and may account for the fact that no larval DoLAs have been backfilled or DoLAs may die before larval stages. Despite the relatively low number of DoLA neurons per embryo, occasionally several DoLA neurons can be found in successive segments (see Fig. $8 \mathrm{~A}$ in Kuwada et al., '90b).

VeLD neuron. At 18-20 hours the VeLD neurons are found in the ventrolateral cord slightly dorsal to the primary motor neurons. These neurons have axons which run ventrally for a short segment and descend in the ventrolateral cord (Figs. 10D, 11B). Application of diI to the ventral cord of 24-25-hour embryos ( $\mathrm{n}=9$; data not shown) demonstrated that the VeLD axons descend in the VLF and not the MLF. In these embryos two discrete tracts, one ventrolateral and the other ventromedial, and, respectively, two sets of neurons, VeLD and reticulospinal interneurons, 

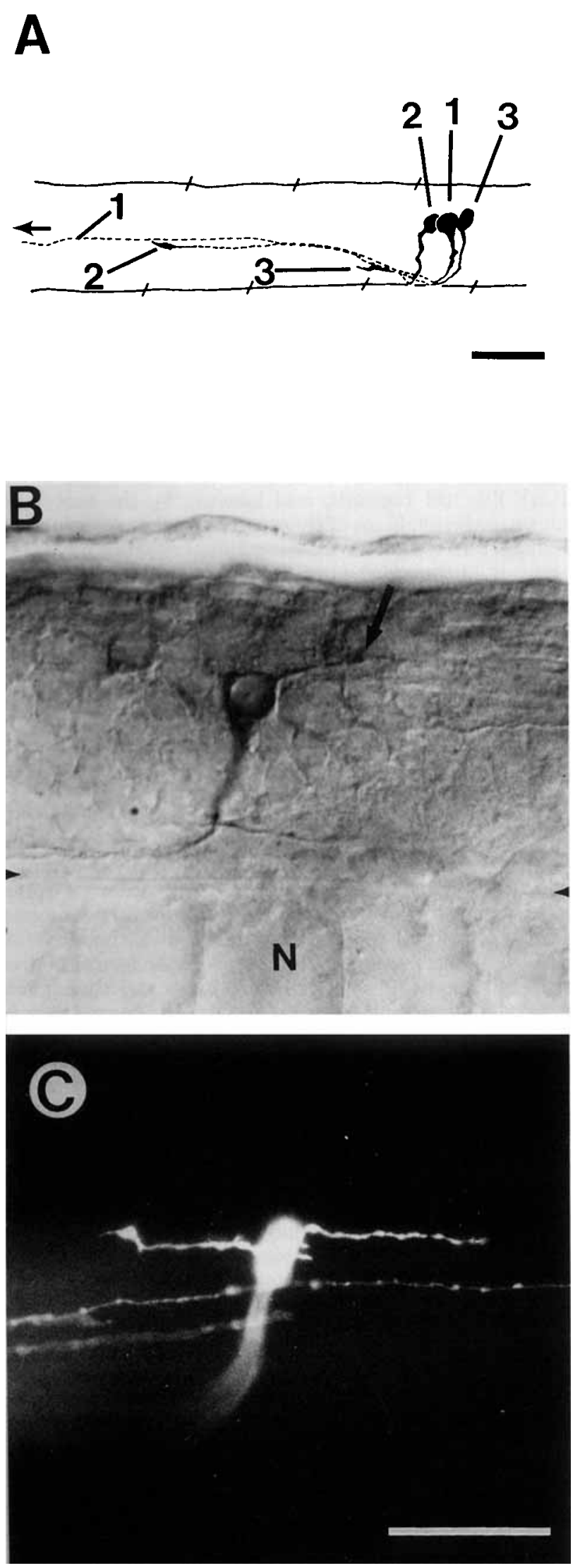

Position of Veld in relation to CAP

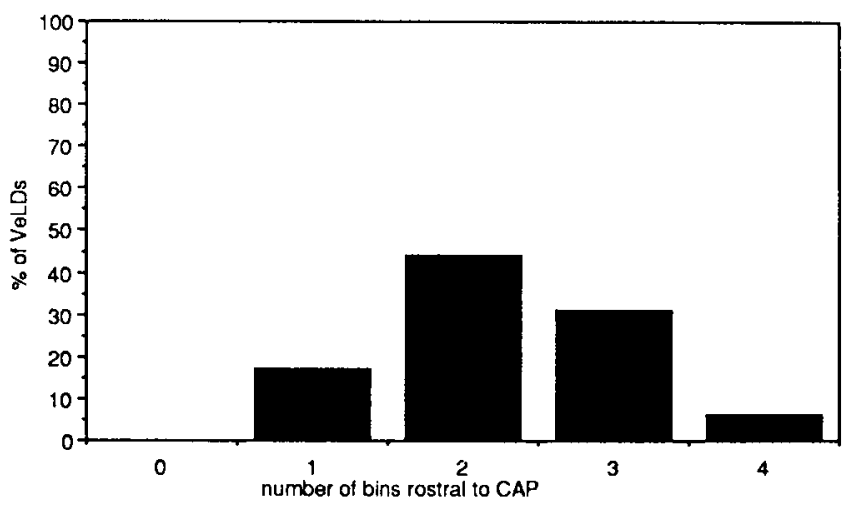

Fig. 15. VeLD neuron is located in a relatively stereotyped position with respect to the $\mathrm{CaP}$ motor neuron. Histogram plotting the position of $29 \mathrm{VeLD}$ neurons relative to the $\mathrm{CaP}$ motor neuron in segments 5-8 of 18-hour embryos labeled with the acetylated tubulin antibody. Each segment was divided into five equal portions (bins) along the anterior/ posterior axis (see Materials and Methods). Bin 0 was designated the position of the CaP soma.

were backlabeled (see also Kuwada, et al., ' $90 \mathrm{~b}$ ). The ventrolateral tract was identified as the VLF due to its position and the fact that it contained the descending axons of the VeLD neurons; the ventromedial tract was identified as the MLF due to its position and the fact that it contained the axons of the reticulospinal neurons (Kimmel et al., '85). In 18-hour embryos there are 1-2 VeLD neurons per hemisegment labeled by the acetylated tubulin antibody with an average of 1.1 VeLD neurons (range: 1-2; segments 5-8 in five embryos) per hemisegment. Compilation of the position of these neurons relative to the segmentally distributed $\mathrm{CaP}$ motor neuron (Myers et al., '86) demonstrates that they have a tendency to be located half-way between consecutive CaP motor neurons (Fig. 15). A $\chi^{2}$ test $\left(\chi^{2}=19\right.$, $\mathrm{df}=4, P<.005$ ) confirmed that the location of the VeLD neuron is not random with respect to $\mathrm{CaP}$. The distribution of VeLD neurons was also determined by intracellular LY injections of all the ventral neurons in a single segment in 23-24-hour embryos $(n=3)$. In each case two VeLD cells per segment were filled. This is similar to the distribution of VeLD cells found in the larval cord (see above) and may indicate that in many segments a second VeLD neuron will develop after 18 hours.

Later embryonic spinal neurons. Three additional spinal neurons initiate axonogenesis after the early neurons: $\mathrm{CiD}$, circumferential ascending $(\mathrm{CiA})$, and commissural bifurcating (CoB) neurons (Fig. 16). These neurons

Fig. 14. One of the ascending commissural neurons is much more developed than the others in each segment and one ascending commissural neuron develops CoPA-like somatic dendrites. A: Camera lucida drawing of $3 \mathrm{LY}$-filled ascending commissural neurons in a 25.5-hour embryo. Neuron 1 had a growth cone 12 segments anterior to its soma while neurons 2 and 3 had much shorter axons. Scale, $50 \mu \mathrm{m}$. B: Micrograph of an anti-CON1 labeled ascending commissural neuron with a prominent posterior dendrite in a 32-hour embryo. The axons of contralateral commissural neurons are also labeled. Arrowheads, ventral border of the cord; $\mathrm{N}$, notochord. $\mathrm{C}$ : Fluorescence micrograph of a diI backfilled ascending commissural neuron with both anterior and posterior dendrites in a 48-hour embryo. DiI labeled longitudinal axons ventral to the dendrites are part of other cells. Scale for B and C, $25 \mu \mathrm{m}$. 
A

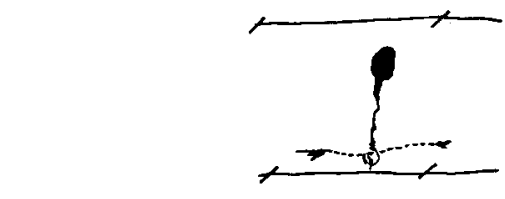

B

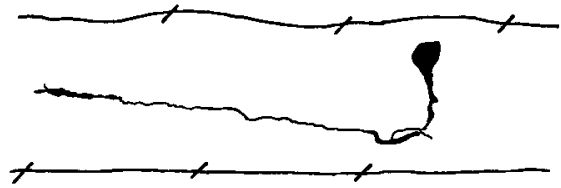

C
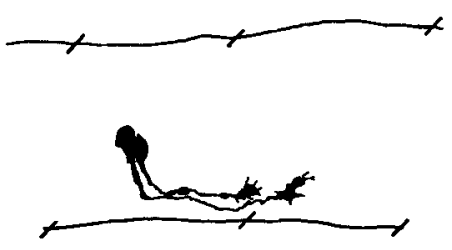

Fig. 16. Spinal neurons found in older (24-25-hour) embryos. Camera lucida drawings of LY filled neurons. A: CoB neuron. B: CiA neuron. C: Pair of CiD neurons. Scale for all panels, $50 \mu \mathrm{m}$.

have been identified in older embryos by intracellular LY injections $(11,13$, and 19 fills, respectively, for $\mathrm{CiD}, \mathrm{CiA}$, and $\mathrm{CoB}$ ). It is possible that additional neuronal classes exist in these older embryos.

The $\mathrm{CiD}, \mathrm{CiA}$, and $\mathrm{CoB}$ neurons are first evident at 22-23 hours. We cannot rule out that they may exist at much earlier stages, but these cells are not evident in acetylated tubulin labeled embryos and have not been encountered in the approximately 180 intracellular LY fills and 30 diI injected embryos at stages earlier than 22 hours.

The $\mathrm{CoB}$ neuron is a commissural neuron which has a relatively small cell body located in a dorsolateral position (Fig. 16A). These cells have axons that cross the ventral midline and bifurcate to send ascending and descending longitudinal axons in the ventrolateral cord. This differs from the CoPA and CoSA axons that run longitudinally in the DLF.

The embryonic CiD neuron is similar to the larval CiD neuron. At 25 hours these neurons have growth cones which have first extended ventrally, then turned caudally (Fig. 16C). Later CiD neurons have longitudinal descending axons in a position corresponding to the ventral DLF (data not shown). The $\mathrm{CiA}$ neuron like the $\mathrm{CiD}$ neuron has a dorsal cell body and a circumferential axon that turns longitudinally ipsilateral to its cell body (Fig. 16B). Following the circumferential portion, however, the $\mathrm{CiA}$ axon runs along an oblique trajectory both dorsally and rostrally before ascending in a position corresponding to the ventral DLF.

\section{DISCUSSION \\ The spinal cord of zebrafish embryos is a simple system}

The early cord of embryonic zebrafish (18-20 hours of development) is composed of a limited number of cells. One hemisegment consists of neuroepithelial cells, approximately 20 floor plate cells, which make up the ventral floor of the cord (Kuwada et al., '90a), and 18 laterally placed cells, which presumably represent post-mitotic cells. Eight to eleven of these lateral cells are neurons that have begun axonogenesis by this time. These fall into five classes of identified neurons. There are three primary motor neurons (Myers et al., '86), approximately three RB neurons, 1-3 ascending commissural neurons, at most a single DoLA neuron, and one VeLD neuron. The identity of the other neurons that have not projected axons at this early stage is not known. However, some of them may be later developing ascending commissural, $\mathrm{CoB}, \mathrm{CiA}$, and $\mathrm{CiD}$ neurons. These conclusions are based on three lines of evidence: intracellular LY fills, diI backfills, and labeling by the acetylated tubulin antibody. None of these methods alone conclusively demonstrates that all of the early spinal neurons have been identified. However, the conclusions seem reasonable since all three methods revealed the same set of early spinal neurons.

These same data suggest, although do not prove, that the acetylated tubulin antibody likely recognizes most if not all embryonic axons. This hypothesis is supported by the findings that the antibody labels all tracts in the brain of zebrafish embryos (Chitnis and Kuwada, '90) and heavily labels a subset of neurons but lightly labels presumably all neurons in the nematode (Siddiqui et al., '89).

The distribution of spinal neurons run the gamut from being strictly segmental like the RoP, MiP, and CaP motor neurons (Myers, et al., '86) to being randomly distributed like the RB neurons (Myers, et al., '90). Amongst spinal interneurons the distribution of CON1 positive commissural neurons are the best documented. Although most often there is a single CON1 positive commissural neuron per hemisegment, their distribution is not strictly segmental. Of the other early neurons the VeLD neurons may be segmentally distributed while the DoLA neurons are probably not. Precise knowledge of the distribution of neurons will have to wait for specific markers for individual cell types to become available.

Of the later developing neurons the CiD neuron has been found in the larval cord while the $\mathrm{CiA}$ and $\mathrm{CoB}$ neurons have not. It is possible that $\mathrm{CiA}$ neurons have not been recognized in our larval HRP backfills since the rostrocaudal portion of their axons may have been confused with those of the ascending commissural neurons, CoPA and CoSA. Similarly larvail Evi' neurons may have been mistaken for CoSA neurons since their ventral longitudinal axons could have been obscured by the heavily labeled MLF axons.

\section{Primary and secondary spinal neurons}

The axial motor neurons fall into primary and secondary classes based on their number, morphology, site of termination, and time of birth and axonogenesis (Myers '85; Myers et al., '86). The three primary motor neurons have large cell bodies, thick axons, large innervation fields, are born very early, and project growth cones early. The secondary motor neurons are larger in number, have smaller cell bodies, 
thinner axons, smaller innervation fields, are born later, and project growth cones later in development. The best case that other neurons are organized in a similar way exists for the ascending commissural neurons in the larval cord. There is usually a single CoPA neuron per hemisegment which has a very large cell body with characteristic dendrites protruding from them and a thick and very long axon. The CoSA neurons are larger in number, have smaller cell bodies with no dendrites protruding from them, and have thin axons. Several indirect observations suggest that in the embryo the earliest differentiating ascending commissural neurons may correspond to $\mathrm{CoPA}$ neurons and the later ones to CoSA neurons. 1) Intracellular fills indicate that the earliest ascending commissural neurons have large cell bodies, which are distributed and possess large caliber axons like larval CoPAs, while the later cells have smaller somata with smaller caliber axons and are much more numerous like larval CoSAs. 2) Intracellular and diI fills of the large commissural neuron demonstrate that they develop somatic dendrites characteristic of CoPA neurons. 3) Up to 28 hours of embryonic development anti-CON1 labels only a subset of commissural cells sharing the characteristics of CoPA. Thus the large early commissural neurons are at least initially antigenically distinct from other commissural neurons.

\section{Comparisons with spinal neurons in the Japanese medaka fish and amphibians}

There appears to be a considerable amount of homology between the spinal neurons of the zebrafish (this and the companion paper, Kuwada et al., '90b), Japanese medaka fish (Kuwada, '86), and Xenopus (Roberts and Clarke, '82) embryos. RB, commissural, and DoLA-like neurons are found in all three embryos. The DoLA-like cells are in each case relatively rare, located near the DLF, and have prominent ascending axons and numerous longitudinal dendrites. The dorsolateral commissural and the commissural neurons in Xenopus appear to be homologous with zebrafish CoPA and CoSA neurons, respectively. There are relatively few dorsolateral commissural and CoPA neurons, and they are both multipolar with prominent longitudinal dendrites; there are considerably more commissural and CoSA neurons, and they are unipolar. The ascending and descending interneurons in Xenopus are similar to the CiA and $\mathrm{CiD}$ or VeLD neurons, respectively. Furthermore, the Xenopus contains ciliated cerebrospinal-fluid-contacting neurons, which project ascending axons in the ventral cord and appear to be GABAergic (Dale et al., ' 87 ). So far we have not seen similar cells in the zebrafish.

Commissural axons projecting to supraspinal levels have been described in classical anatomical studies (reviewed in Ariens Kappers et al., '36). They are thought to exist in lower as well as higher vertebrates and may be the phylogentetically oldest secondary sensory tract to the medulla oblongata. In amphibians (Herrick, '17; '30) and fish (Murakami and Ito, '85; Ito et al., '86) spinal commissural cells project to the midbrain and thalamus (the projection variously referred to as spinal lemniscus, tractus spino tectalis, and tractus spino-thalamicus). This spinothalamic projection closely resembles the projection by the ascending commissural neurons described in this study.

The simplicity of the early zebrafish cord combined with the ability to utilize techniques to analyze identified growth cones has allowed us to delineate pathfinding by most of the early spinal neurons (Kuwada et al., '90b). Furthermore, the cells and structures encountered by identified growth cones have been characterized (Kuwada et al., '90a). We can now utilize procedures to manipulate the environment of these growth cones to test a number of growth cone guidance mechanisms in the embryonic zebrafish.

\section{ACKNOWLEDGEMENTS}

We thank G. Piperno for the monoclonal antibody against acetylated tubulin, P. Knafl and B. Morin for technical assistance, and $\mathrm{R}$. Hume for critically reading the manuscript. This work was supported by grants from NIH (NS 24848), Office of the Vice-President for Research at the University of Michigan, a Basil O'Connor Scholar Award from the March of Dimes Birth Defects Foundation to JYK, and a fellowship from the Swiss National Science Foundation to RRB.

\section{LTTERATURE CITED}

Ariens Kappers, C.U., G.C. Huber, and E.C. Crosby (1936) The Comparative Anatomy of the Nervous System of Vertebrates Including Man. New York: MacMillan.

Bastiani, M.J., and C.S. Goodman (1986) Guidance of neuronal growth cones in the grasshopper embryo. III. Recognition of a specific glial pathways. J. Neurosci. 6:3542-3551.

Bastiani, M.J., S. du Lac, and C.S. Goodman (1986) Guidance of neuronal growth cones in the grasshopper embryo. I. Recognition of a specific axonal pathway by the pCC neuron. J. Neurosci. 6:3518-3531.

Chitnis, A.B., and J.Y. Kuwada (1990) Axonogenesis by identified neurons in the brain of zebrafish embryos. J. Neurosei. 10:1892-1905.

Clarke, J.D.W., B.P. Hayes, S.P. Hunt, and A. Roberts (1984) Sensory physiology, anatomy and immunohistochemistry of Rohon-Beard neurons in embryos of Xenopus laevis. J. Physiol. 348:511-525.

Dale, N., A. Roberts, O.P. Ottersen, and J. Storm-Mathisen (1987) The morphology and distribution of "Kolmer-Agduhr cells," a class of cerebrospinal-fluid-contacting neurons revealed in the frog embryo spinal cord by GABA immunohistochemistry. Proc. R. Soc. Lond. B. 232:193-203.

du Lac, S., M.J. Bastiani, and C.S. Goodman (1986) Guidance of neuronal growth cones in the grasshopper embryo. II. Recognition of a specific axonal pathway by the aCC neuron. J. Neurosci. $6: 3532-3541$.

Eisen, J.S., P.Z. Myers, and M. Westerfield (1986) Pathway selection by growth cones of identified motoneurons in live zebrafish embryo. Nature. 320:269-271.

Goodman, C.S., M.J. Bastiani, C.Q. Doe, S. du Lac, S.L. Helfand, J.Y. Kuwada, and J.B. Thomas (1984) Cell recognition during neuronal development. Science 225:1271-1279.

Herrick, C.J. (1917) The internal structure of the midbrain and thalamus of Necturus. J. Comp. Neurol. 28:215-348.

Herrick, C.J. (1930) The medulla oblongata of Necturus. J. Comp. Neurol. 50:1-96.

Honig, M.G., and R.I. Hume (1986) Fluorescent carbocyanine dyes allow living neurons of identified origin to be studied in long-term cultures. J. Cell Biol. 103:171-187.

Ito, H., T. Murakami, T. Fukuoka, and R. Kishida (1986) Thalamic fiber connections in a teleost (Sebastiscus marmoratus): visual, somatosensory, octavolateral, and cerebellar relay region to the telencephalon. J. Comp. Neurol. 250:215-227.

Kimmel, C.B., S.L. Powell, and W.K. Metcalfe (1982) Brain neurons which project to the spinal cord in young larvae of the zebrafish. J. Comp. Neurol. 205:112-127.

Kuwada, J.Y. (1986) Cell recognition by neuronal growth cones in a simple vertebrate embryo. Science 233:740-746.

Kuwada, J.Y., A.B. Chitnis, and L.A. Lindamer (1987) Stereotyped pathfinding by identified growth cones of the embryonic cord. Soc. Neurosci. Abst. 13:1220.

Kuwada, J.Y., R.R. Bernhardt, and A.B. Chitnis (1990a) Pathfinding by identified growth cones in the zebrafish spinal cord. J. Neurosci. 10:1229-1308. 
Kuwada, J.Y., R.R. Bernhardt, and N. Nguyen (1990b) Development of spinal neurons and tracts in the zebrafish embryo. J. Comp. Neurol. 302:617-628.

Lamborghini, J.E. (1980) Rohon-Beard cells and other large neurons in Xenopus embryos originate during gastrulation. J. Comp. Neurol. 189 : 323-333.

Mendelson, B. (1986) Development of reticulospinal neurons of the zebrafish. II. Early axonal outgrowth and cell body position. J. Comp. Neurol. 251:172-184.

Murakami, T., and H. Ito (1985) Long ascending projections of the spinal dorsal horn in a teleost, Sebastiscus marmoratus. Brain Res. 346:168170.

Myers, P.Z. (1985) Spinal motoneurons in the larval zebrafish. J. Comp. Neurol. 236:555-561.

Myers, P.Z., J. Eisen, and M. Westerfield (1986) Development and axonal outgrowth of identified motoneurons in the zebrafish. J. Neurosci. 6:2278-2289.

Myers, P.Z., Metcalfe, W.R., and C.B. Kimmel (1990) Rohon-Beard and trigeminal sensory neurons show common patterns of early development in zebrafish. Submitted.
Patel, N.H., E. Martin-Blanco, K.G. Coleman, S.J. Poole, M.C. Ellis, T.B. Kornberg, and C.S. Goodman (1989) Expression of engrailed protein in arthropods, annelids, and chordates. Cell. 58:955-968.

Piperno, G., and M.T. Fuller (1985) Monoclonal antibodies specific for an acetylated form of $\alpha$-tubulin recognize the antigen in cilia and flagella from a variety of organisms. J. Cell Bio. 101:2085-2094.

Raper, J.A., M.J. Bastiani, and C.S. Goodman (1984) Pathfinding by neuronal growth cones in grasshopper embryos. IV. The effects of ablating the $\mathrm{A}$ and $\mathrm{P}$ axons upon the behavior of the $\mathrm{G}$ growth cone. $\mathrm{J}$. Neurosci, 4:2339-2345.

Roberts, A., and J.D.W. Clarke (1982) The neuroanatomy of an amphibian embryo spinal cord. Phil. Trans. R. Soc. Lond. B 296:195-212.

Siddiqui, S.S., E. Aamondt, F. Rastinejad, and J. Culotti (1989) Anti-tubulin monoclonal antibodies that bind to specific neurons in Caenorhabditis elegans. J. Neurosci. 9:2963-2972.

Taghert, P.H., M.J. Bastiani, R.K. Ho, R.K. and C.S. Goodman (1982) Guidance of pioneer growth cones: Filopodial contacts and coupling revealed with an antibody to Lucifer Yellow. Dev. Biol. 94:391-399. 